\title{
Disease-related adult malnutrition in tertiary health care settings in Sri Lanka
}

\author{
Jayatissa R ${ }^{1}$, Weerasekara WMSK ${ }^{2}$, Ganga MWDWL 3 , Jayaweera JRT ${ }^{4}$, Pigera ADGSB ${ }^{4}$, Samarasekara TG ${ }^{4}, \mathrm{Saparamadu} \mathrm{AAGH}^{4}$, \\ Kurukulasuriya $\mathrm{S}^{5}$, MallawaArachchi $\mathrm{S}^{5}$, Jayasekara $\mathrm{P}^{6}$ and Rushdi $\mathrm{A}^{7}$ \\ ${ }^{1}$ Consultant Medical Nutritionist, Department of Nutrition, Medical Research Institute, Sri Lanka \\ ${ }^{2}$ Medical Nutrition Unit, Teaching Hospital, Kandy, Sri Lanka \\ ${ }^{3}$ Medical Nutrition Unit, Cancer Hospital, Maharagama, Sri Lanka \\ ${ }^{4}$ Medical Nutrition Unit, National Hospital of Sri Lanka \\ ${ }^{5}$ North Colombo Teaching Hospital, Sri Lanka \\ ${ }^{6}$ National Respiratory Disease Hospital Welisara, Sri Lanka \\ ${ }^{7}$ South Colombo Teaching Hospital, Sri Lanka
}

\begin{abstract}
Background: Despite availability of high end medical advances in tertiary care settings, diseases related malnutrition (DRM) have emerged worldwide. Published studies revealed prevalence of malnutrition in Sri Lanka ranged from 24-74\%. This study aimed at screening for malnutrition using anthropometry to determine the prevalence in patients admitted to the tertiary care settings.
\end{abstract}

Methods: A cross-sectional cluster study was conducted in randomly selected 6 tertiary care settings among 774 adults patients admitted from $25^{\text {th }}$ October to $28^{\text {th }}$ November 2016. DRM was defined as body mass index (BMI) less than $18.5 \mathrm{~kg} / \mathrm{m}^{2}$ and mid upper arm circumference (MUAC) less than $22 \mathrm{~cm}$ in women and $23 \mathrm{~cm}$ in men.

Results: Mean age was $52.5(\mathrm{SD}=15.5)$ years and $51.6 \%$ were male. Mean BMI and MUAC was $22.1(\mathrm{SD}=5.2) \mathrm{kg} / \mathrm{m}^{2}$ and $26.1(\mathrm{SD}=4.5) \mathrm{cm}$. The prevalence of severe malnutrition and overweight/obesity was $9.2 \%$ and $28.1 \%$ respectively. The prevalence of DRM was $25.9 \%$ (BMI definition) and 21.0\% (MUAC definition). Significantly high level of DRM was observed in men and $\geq 70$ years. Malnutrition was most common among patients with pulmonary diseases. MUAC and BMI correlated significantly $(r=0.87 ; \mathrm{p}=0.000)$ and malnutrition by the two methods showed good agreement $(\mathrm{k}=0.69 ; \mathrm{p}=0.000)$

Conclusions: One fourth of patients are admitted to tertiary care hospitals had DRM. MUAC can be utilized as a screening tool to identify the patients after admission. Nutrition screening and assessment should be integrated in the routing care plan of patients to prevent further deterioration.

\section{Introduction}

Disease-related malnutrition (DRM) is a specific type of malnutrition caused by a coexisting disease. European Society of Parenteral and Enteral Nutrition (ESPEN) identify DRM as two categories; disease-specific inflammatory and non-inflammatory [1]. Even though the DRM in hospitalized patients was recognized as early as in 1974, it is still remain as a public health issue in both developed and developing countries $[2,3]$. Several studies show the worldwide prevalence of malnutrition and at risk of malnutrition in hospitals are between $40-70 \%$ [2,4-8]. Prevalence of disease-related malnutrition varied between countries; Philippines (73\%), Canada (51\%), Brazil (48\%), Vietnam (33\%), Singapore (29\%) and Netherland (14\%) [2-4,7-9].

DRM is divided into DRM with inflammation, which is a catabolic condition triggered by a disease-specific inflammatory response and DRM without inflammation linked mainly to non-inflammatory etiological mechanism. Sub types of DRM with inflammation are chronic DRM with a milder inflammatory response (cancer cachexia and other disease-specific cachexia) and acute disease or injury-related malnutrition with a strong inflammatory response [1]. The effect of malnutrition on disease prognosis is well established. Malnourished patients develop more complications, have a higher mortality rate, longer length of hospital stay and have a higher rate of readmission [10-
14]. Early identification of DRM in hospitalized patients will enable effective management for better disease outcome as well as reduce health care cost [15]. Therefore, nutrition screening and identifying patients with malnutrition or at risk of malnutrition should be an integral part of disease management [8].

Limited studies conducted in Sri Lanka have reported prevalence figures between $24-71.4 \%$, with a higher prevalence in the older adults with bronchial asthma (71.4\%), chronic obstructive pulmonary disease (66.6\%), heart disease (5-25\%) and chronic kidney disease (24\%) [1618]. However, DRM is frequently under-recognised and under-treated. Therefore, the aim of the present study was to determine the prevalence of DRM in tertiary care settings and to identify a simple screening tool to be used by the busy health professionals.

Correspondence to: Renuka Jayatissa, Head, Department of Nutrition, Medical Research Institute, Dr Danister De Silva Mawatha, Colombo 08, Sri Lanka, Tel: 0094777788444; E-mail: renukajayatissa@ymail.com

Key words: disease-related malnutrition, BMI, MUAC, adults, screening

Received: October 20, 2017; Accepted: November 07, 2017; Published: November 10, 2017 


\section{Methods}

This was a hospital based descriptive cross sectional study. Patients who were pregnant, below 18 years, with psychiatric illnesses, unconscious, on dialysis, critically ill, who had physical impairments which makes getting anthropometric measurement impossible and patients discharged within 24 hours were excluded from the study.

Sample size was calculated considering the prevalence of malnutrition is $50 \%$ and $95 \%$ confidence interval with $5 \%$ error. Design effect was taken as 1.8 . Total sample size was $836 ; 140$ participants from each hospital. Six out of 20 tertiary care hospitals were randomly selected; one ward was selected randomly from each hospital. All patients within the inclusion criteria who were admitted to the selected wards were included after informed written consent was obtained. Ethical clearance was obtained from the faculty of medicine, University of Kelaniya. Data was collected until fulfil the sample size in each hospital.

Data was collected by the medical officers of nutrition who have been trained and standardized for anthropometric measurements. Selected wards were visited daily by the data collectors and the eligible patients were recruited from $25^{\text {th }}$ of October to $28^{\text {th }}$ of November 2016. Demographic data and type of the disease was gathered and weight, height and mid upper arm circumference was measured.

Weight and height was measured using an electronic weighing scale (seca 813 ) with a precision of $100 \mathrm{~g}$ and a stadiometer (seca 217) with a precision of $1 \mathrm{~mm}$ respectively. Mid-upper arm circumference (MUAC) was measured using non stretchable measuring tapes to the nearest $0.5 \mathrm{~cm}$ (Seca). All the equipment were calibrated and standardized prior to the study.

\section{Data analysis}

Body-mass-index (BMI) was calculated based on weight in kilogram divided by height in meters squared $\left(\mathrm{kg} / \mathrm{m}^{2}\right)$. DRM of adult is defined when $\mathrm{BMI}<18.5 \mathrm{~kg} / \mathrm{m}^{2}$ according to ESPEN guidelines [19]. When MUAC $<23 \mathrm{~cm}$ in men and $<22 \mathrm{~cm}$ in women is considered as malnutrition [20]. Type of illness was categorized as surgical (trauma, minor and major surgery, burn, fracture etc); medical (acute renal failure, dengue, viral fever, diabetes, hypertension, hepatitis etc.); oncology (all cancers); pulmonary (asthma, tuberculosis, chronic obstructive pulmonary disease etc.) and cardiovascular (angina, ischaemic heart disease, cardiomyopathy, myocardial infarction, valvular disease etc.). All analysis was performed using IBM SPSS statistics 23.0. Differences were tested using Chi square test and $\mathrm{p}<0.05$ considered as statistically significant. Agreement between malnutrition described as ESPEN and MUAC was measured by kappa statistics and correlation between the two methods was assessed by Pearson's correlation coefficient.

\section{Results}

Total number of patient recruited was 774 , which is $93 \%$ of the calculated sample size. Patient's characteristics are presented in Table 1. Age of the patients ranged from 18-89 years and half was belonged to $50-69$ years. The mean age was $52.5(\mathrm{SD}=15.5)$ years. There were $51.6 \%$ males. Patients were classified according to the type of illness as shown in Table 1; surgical (24.8\%), medical (27.0\%), oncology (31.3\%), pulmonary (8.5\%) and cardiovascular (8.4\%). According to the WHO criteria for BMI classifications, $9.2 \%, 6.1 \%$ and $10.5 \%$ were severely, moderately and mildly malnourished respectively and $26.5 \%$ were overweight or obese [21]. Mean BMI and MUAC of the study population was $22.1(\mathrm{SD}=5.2) \mathrm{kg} / \mathrm{m} 2$ and $26.1(\mathrm{SD}=4.5) \mathrm{cm}$ respectively.
Table 1. Characteristics of patients

\begin{tabular}{|c|c|c|}
\hline Characteristics & $\mathbf{n}$ & $\%$ \\
\hline \multicolumn{3}{|l|}{ Age (Years) } \\
\hline $18-49$ & 292 & 37.7 \\
\hline $50-69$ & 387 & 50.0 \\
\hline$\geq 70$ & 95 & 12.3 \\
\hline \multicolumn{3}{|l|}{ Gender } \\
\hline Male & 399 & 51.6 \\
\hline Female & 375 & 48.4 \\
\hline \multicolumn{3}{|l|}{ BMI groups (WHO criteria) } \\
\hline$<16.0$ (severe malnutrition) & 71 & 9.2 \\
\hline 16.0-16.9 (moderate malnutrition) & 47 & 6.1 \\
\hline 17.0-18.49 (mild malnutrition) & 82 & 10.5 \\
\hline $18.5-24.9$ (normal) & 373 & 47.9 \\
\hline 25.0-29.9 (overweight) & 150 & 19.3 \\
\hline 30.0-34.9 (obesity) & 39 & 7.2 \\
\hline$\geq 35.0$ (morbid obesity) & 12 & 1.6 \\
\hline \multicolumn{3}{|l|}{ Type of illness } \\
\hline Surgical & 192 & 24.8 \\
\hline Medical & 209 & 27.0 \\
\hline Oncology & 242 & 31.3 \\
\hline Pulmonary & 66 & 8.5 \\
\hline Cardiovascular & 65 & 8.4 \\
\hline \multirow[t]{2}{*}{ Total } & 774 & 100.0 \\
\hline & Mean & SD \\
\hline Age in years & 52.5 & 15.5 \\
\hline BMI $\left(\mathrm{kg} / \mathrm{m}^{2}\right)$ & 22.1 & 5.2 \\
\hline MUAC (cm) & 26.1 & 4.5 \\
\hline
\end{tabular}

\section{Disease-related malnutrition}

Table 2 shows the prevalence of malnutrition defined by ESPEN and MUAC was $25.9 \%$ and $21.0 \%$ respectively. The prevalence of malnutrition was significantly higher in men than female according to both classifications and patients $>70$ years of age group than other age groups. There were statistically significant differences in the prevalence of malnutrition by the type of illness by ESPEN and MUAC definitions (surgical $15.1 \%$ vs $11.0 \%$, medical $20.1 \%$ vs $15.5 \%$, oncology $31.8 \%$ vs $25.6 \%$, pulmonary $67.7 \%$ vs $63.6 \%$ and cardiovascular $12.3 \%$ vs $4.6 \%$ ) respectively.

\section{Agreement and correlation between methods}

Table 3 shows good agreement between ESPEN cut-off and MUAC criteria for classifying malnutrition with $\mathrm{k}=0.69$ ( $\mathrm{SE}=0.03$ ) and $90.9 \%$ observed agreement. BMI and MUAC had a significantly positive correlation $(\mathrm{r}=0.87 ; \mathrm{P}=0.000)$.

\section{Discussion}

This study was conducted using ESPEN and MUAC cut-off levels to identify the easy tool for screening purposes. Many studies have used combination of BMI and intention weight loss as screening tools to identify diseases related malnutrition $[16,22]$, some used BMI alone $[23,24]$ and others both criteria were used $[2,25,26]$. This study revealed that the prevalence of DRM was $25.9 \%$ and $21.0 \%$ at tertiary care settings respectively. Similar prevalence are observed in previous studied conducted in Sri Lanka. A German hospital study has shown only $4.1 \%$ [25] while in Vietnam it was 33.3\% [27]. Severe malnutrition was $9.7 \%$ in our study which is higher than in Vietnam (8\%) study [27]. Overweight and obesity was $25.4 \%$ in this study. In German it was very high, $51.9 \%$ while in Vietnam it was only $6.6 \%$ [25,27].

This study shows that DRM varies significantly with the gender as well as with the type of disease and age. Naderi, et al. [14] also found 
Table 2. Malnutrition in relation to basic characteristics and type of illness

\begin{tabular}{|c|c|c|c|c|}
\hline \multirow[b]{2}{*}{ Characteristics } & \multicolumn{4}{|c|}{ Malnutrition\% (95\% Confidence Interval) } \\
\hline & WHO & $\mathbf{N}$ & MUAC & $\mathbf{N}$ \\
\hline \multicolumn{5}{|c|}{ Age (Years) } \\
\hline $18-49$ & $\begin{array}{c}25.3 \\
(22.1-28.4)\end{array}$ & 292 & $\begin{array}{c}15.3 \\
(12.7-17.9)\end{array}$ & 274 \\
\hline $50-69$ & $\begin{array}{c}24.3 \\
(21.3-27.3)\end{array}$ & 387 & $\begin{array}{c}22.1 \\
(19.1-25.1)\end{array}$ & 384 \\
\hline \multirow[t]{2}{*}{$\geq 70$} & $\begin{array}{c}33.7 \\
(30.4-37.0)\end{array}$ & 95 & $\begin{array}{c}32.6 \\
(28.3-34.9)\end{array}$ & 95 \\
\hline & \multicolumn{2}{|c|}{$P=0.1$} & \multicolumn{2}{|c|}{$P=0.001$} \\
\hline \multicolumn{5}{|c|}{ Gender } \\
\hline Male & $\begin{array}{c}32.6 \\
(29.3-35.9)\end{array}$ & 399 & $\begin{array}{c}25.3 \\
(22.2-28.4)\end{array}$ & 395 \\
\hline \multirow[t]{2}{*}{ Female } & $\begin{array}{c}18.7 \\
(15.9-27.5)\end{array}$ & 375 & $\begin{array}{c}16.2 \\
(13.3-18.5)\end{array}$ & 358 \\
\hline & $P=0.000$ & & $P=0.001$ & \\
\hline \multicolumn{5}{|c|}{ Type of illness } \\
\hline Surgical & $\begin{array}{c}15.1 \\
(11.9-16.9)\end{array}$ & 192 & $\begin{array}{c}11.0 \\
(8.2-12.6)\end{array}$ & 173 \\
\hline Medical & $\begin{array}{c}20.1 \\
(17.5-23.1)\end{array}$ & 209 & $\begin{array}{c}15.5 \\
(13.2-18.4)\end{array}$ & 207 \\
\hline Oncology & $\begin{array}{c}31.8 \\
(28.5-35.1)\end{array}$ & 242 & $\begin{array}{c}25.6 \\
(22.5-28.7)\end{array}$ & 242 \\
\hline Pulmonary & $\begin{array}{c}67.7 \\
(66.5-72.9)\end{array}$ & 66 & $\begin{array}{c}63.6 \\
(61.8-68.6)\end{array}$ & 66 \\
\hline \multirow[t]{2}{*}{ Cardiovascular } & $\begin{array}{c}12.3 \\
(9.6-14.2)\end{array}$ & 65 & $\begin{array}{c}4.6 \\
(1.8-4.2)\end{array}$ & 65 \\
\hline & $P=0.000$ & & $P=0.000$ & \\
\hline Total & $\begin{array}{c}25.9 \\
(22.8-29.1)\end{array}$ & 774 & $\begin{array}{c}21.0 \\
(18.0-23.9)\end{array}$ & 753 \\
\hline
\end{tabular}

Table 3. Agreement between identification of disease-related malnutrition using ESPEN, WHO and MUAC definitions

\begin{tabular}{|c|c|c|c|c|}
\hline ESPEN & \multicolumn{2}{|c|}{ MUAC } & k (SE) & P \\
\hline & Malnutrition & No malnutrition & & \\
\hline Malnutrition & 135 & 63 & $0.69(0.03)$ & 0.000 \\
\hline No malnutrition & 22 & 533 & & Observed agreement $=90.9 \%$ \\
\hline \multicolumn{4}{|l}{} \\
\hline
\end{tabular}

more male patients with malnutrition than females similar to findings of our study. However, gender had no association with the prevalence of malnutrition in one study [2]. This study shows the older patients (> 70 years) having the highest prevalence of malnutrition $(33 \%)$. This may be due to low sample size in this age group and need more representative study to confirm it. Dominguez [2] also found that older patients (above 60 years) were more malnourished and it was supported by Chakravarty, et al. [22] and Kruizenga, et al. [7] also. But Naderi, et al. [14] found younger patients (18-29 year) to be more malnourished.

Prevalence of malnutrition was different according to the type of illness. It was highest in pulmonary which was $67.7 \%$ while lowest $12.3 \%$ was seen in cardiovascular patients. Similar findings were observed in a study conducted among elderly medical ward patients in Sri Lanka. It showed the highest prevalence among chronic obstructive lung disease patients which was $66.6 \%$ by the nutrition screening tool Mini Nutritional Assessment [16]. A study in Vietnam found the highest prevalence of malnutrition (51.3\%) among patients in surgery wards but respiratory ward patients also had a high prevalence of $40.9 \%$ in a tertiary care hospital [27]. Dominguez [2] and Kruizenga, et al. [7] noted that patients with malignancies were more malnourished but in another study in Tehran it was highest in patients with gastrointestinal diseases [14].
When we used MUAC to define malnutrition, it showed MUAC and BMI had good agreement with almost $90 \%$ correctly classified malnutrition. A similar agreement of these two indices has been found by other authors [28]. It highlights the use of both BMI and MUAC can be acceptable for screening in our settings as they are simple and less resource driven. MUAC can be used even with severally ill patients and patients who cannot be weighed or measure their heights. Most of patients are unaware about their original weight in our setting. Hence it is difficult to determine the unintentional weight loss to apply validated screening tools such as NRS-2002. MUAC will provide opportunity for busy nursing staff to easily carry out the screening which can be followed by the comprehensive assessment by the nutrition staff.

Limitation of our study was severely ill patients were not included to determine the prevalence of DRM, who may be the most malnourished. Biochemical indices were not collected to classify the types of DRM. It should be cautious in interpreting the prevalence of malnutrition in pulmonary and cardiovascular diseases and among patients $\geq 70$ years due to small sample sizes.

\section{Conclusion}

This study has shown one fourth of adult patients admitted to tertiary health care settings in Sri Lanka had DRM. One out of ten were severely malnourished. Highest prevalence was observed with patients with pulmonary diseases. MUAC can be used as a screening tool to identify DRM in our settings to integrate the comprehensive medical nutrition therapy.

\section{Acknowledgments}

We thank Directors, staff of hospitals and all the doctors in the medical nutrition units for the extensive support provided during the data collection.

\section{Authour contributions}

Renuka Jayatissa (RJ) and WMSK Weerasekara (SW) were responsible for the study concept, study design, data analysis and critical revision of the manuscript for important scientific content. Other 9 investigators supported with acquisition of data and performing interviews. All 11 authors equally contributed to preparation of manuscript.

\section{Conflict of interest}

The authors declare no conflict of interest.

\section{References}

1. Cederholm T, Barazzoni R, Austin P, Ballmer P, Biolo G, et al. (2017) ESPEN guidelines on definitions and terminology of clinical nutrition. Clinical Nutr 36: 49-64. [Crossref]

2. Dominguez RJ (2013) Burden of Malnutrition in a Tertiary Care Hospital in Baguio City. SAGE Open 3: 1-7.

3. Thi P, Huong T, Lam NT, Thu NN, Quyen TC, et al. (2014) Prevalence of malnutrition in patients admitted to a major urban tertiary care hospital in Hanoi, Vietnam. Asia Pac J Clin Nutr 23: 437-444.

4. Waitzberg DL, Caiaffa WT, Correia MITITD (2001) Hospital malnutrition: The Brazilian national survey (IBRANUTRI): A study of 4000 patients. Nutrition 17: 573-580.

5. Lim SL, Ong KCB, Chan YH, Loke WC, Ferguson M, et al. (2012) Malnutrition and its impact on cost of hospitalization, length of stay, readmission and 3-year mortality. Clinical Nutrition 31: 345-350.

6. Stratton RJ, Hackston A, Longmore D, Dixon R, Price S, et al. (2004) Malnutrition in hospital outpatients and inpatients: prevalence, concurrent validity and ease of use of the "malnutrition universal screening tool" ('MUST') for adults. Br J Nutr 92: 799-808. 
7. Kruizenga H, Van Keeken S, Weijs P, Bastiaanse L, Beijer S, et al. (2016) Undernutrition screening survey in 564,063 patients: patients with a positive undernutrition screening score stay in hospital 1.4 d longer. Am J Clin Nutr 103: 1026-1032.

8. Lim SL (2014) Malnutrition in hospitalised patients and clinical outcomes?: A missed opportunity?Thesis by publication submitted for the Doctor of Ohilosophy in the School of Exercise and Nutritional Sciences. Queensland University of Techniology. Australia.

9. Allard JP, Keller H, Jeejeebhoy KN, Laporte M, Duerksen DR, et al. (2016) Decline in nutritional status is associated with prolonged length of stay in hospitalized patients admitted for 7 days or more: A prospective cohort study. Clin Nutr 35: 144-152. [Crossref]

10. Barker LA, Gout BS, Crowe TC (2011) Hospital malnutrition: prevalence, identification and impact on patients and the healthcare system. Int J Environ Res Public Health 8: 514-527. [Crossref]

11. Guenter P (2015) Addressing Disease-Related Malnutrition in Hospitalized Patients: A Call for a National Goal. The Joint Commission Journal on Quality and Patient Safety, 41: 469-473.

12. Khalatbari-Soltani S, Marques-Vidal P (2016) Impact of nutritional risk screening in hospitalized patients on management, outcome and costs: A retrospective study. Clin Nutr 35: 144-152. [Crossref]

13. Pontif VAL, Cat U, Salles F, Puc C (2011) Nutrition Status and Risk Factors Associated With Length of Hospital Stay for Surgical Patients. JPEN J Parenter Enteral Nutr 35: 241-224.

14. Naderi Z, Bs HN, Delshad M, Mirmiran P, Azizi F (2012) Prevalence of malnutrition in hospitalized patients in Taleghani hospital in Tehran. J Gorgan Univ Med Sci 13: 97-106.

15. Alberda C, Day AG (2009) The relationship between nutritional intake and clinical outcomes in critically ill patients?: Results of an international multicenter observational study. Intensive Care Med 35: 1728-1737. [Crossref]

16. Bandara RMCJ, Bandara BMR, Abeykoon DMB, Wickramasinghe A, Wijesundara DS, et al. (2011) Assessment of Nutritional Status of Elderly Hospitalised Patients According to Their Co-Morbid Conditions and Educational Levels Using Mini Nutrition Assessment Tool. Proceedings of the Peradeniya University Research Sessions, 16: 156.
17. Pathirana AK, Lokunarangoda N, Ranathunga I, Santharaj WS, Ekanayake R, et al. (2014) Prevalence of hospital malnutrition among cardiac patients: results from six nutrition screening tools. SpringerPlus 3: 412.

18. Dassanayake RT, Gunarathne RMCL, Gunasekara VCDG, De Silva ST (2015) Protein energy malnutrition in patients with chronic kidney disease in Sri Lanka. Sri lanka Medical Association.

19. Cederholm T, Jensen GL (2017) To create a consensus on malnutrition diagnostic criteria: A report from global leadership initiative on malnutrition meeting at the ESPEN congress 2016. Clin Nutr 36: 7-10. [Crossref]

20. James WP, Mascie-Taylor GC, Norgan NG, Bistrian BR, Shetty PS, et al. (1994) The value of arm circumference measurements in assessing chronic energy deficiency in third world adults. Eur J Clin Nutr 48: 883-894.

21. World Health Organisation (1995) Physical status: The use and interpretation of anthropometry; Report of a WHO expert committee; Technical report series No. 854. WHO; Geneva, Switzerland.

22. Chakravarty C, Hazarika B, Goswami L, Ramasubban S (2013) Prevalence of malnutrition in a tertiary care hospital in India. Indian J Crit Care Med 17: 170-173.

23. Kelly IE, Tessier S, Cahill A, Morris SE, Crumley A, et al. (2000) Still hungry in hospital: identifying malnutrition in acute hospital admissions. QJM 93: 93-98.

24. Waitzberg DL, Caiaffa WT, Correia MI (2001) Hospital malnutrition: the Brazilian national survey (IBRANUTRI): a study of 4000 patients. Nutrition 17: 573-580. [Crossref]

25. Pirlich M, Schütz T, Norman K, Gastell S, Lübke HJ, et al. (2006) The German hospital malnutrition study. Clin Nutr 25: 563-572.

26. Vila MP, Herndez J, De Lorenzo AG, Sanz ML, Brosa M. (2010) The burden of hospital malnutrition in Spain: Methods and development of the PREDyCES?? study. Nutricion Hospitalaria 25: 1020-1024.

27. Huong PT, Lam NT, Thu NN, Quyen TC, Lien DT, et al. (2014) Prevalence of malnutrition in patients admitted to a major urban tertiary care hospital in Hanoi, Vietnam. Asia Pac J Clin Nutr 23: 437-444. [Crossref]

28. Luma HN, Eloumou SAFB, Mboligong FN, Temfact E, Donfack OT, et al. (2017) Malnutrition in patients admitted to the medical wards of the Douala General Hospital: a cross sectional survey. BMC Res Notes 10: 238-243.

Copyright: (C2017 Jayatissa R. This is an open-access article distributed under the terms of the Creative Commons Attribution License, which permits unrestricted use, distribution, and reproduction in any medium, provided the original author and source are credited. 